Article

\title{
Substrate Application of 5-Aminolevulinic Acid Enhanced Low-temperature and Weak-light Stress Tolerance in Cucumber (Cucumis sativus L.)
}

\author{
Ali Anwar ${ }^{1,2,+} \mathbb{C}$, Jun Wang ${ }^{1,+}$, Xianchang $\mathrm{Yu}^{1}$, Chaoxing $\mathrm{He}^{1}$ and Yansu $\mathrm{Li}^{1, *}$ \\ 1 Institute of Vegetables and Flowers, Chinese Academy of Agricultural Sciences, Beijing 100081, China; \\ anwarsnu@aol.com (A.A.); wangjun01@caas.cn (J.W.); xcyu1962@163.com (X.Y.); hechaoxing@caas.cn (C.H.) \\ 2 Graduate School of International Agricultural Technology and Crop Biotechnology Institute/Green Bio \\ Science \& Technology, Seoul National University, Pyeongchang 25354, Korea \\ * Correspondence: liyansu@caas.cn \\ + These authors contributed equally to this work.
}

Received: 9 March 2020; Accepted: 27 March 2020; Published: 29 March 2020

\begin{abstract}
Aminolevulinic acid (ALA) is a type of nonprotein amino acid that promotes plant stress tolerance. However, the underlying physiological and biochemical mechanisms are not fully understood. We investigated the role of ALA in low-temperature and weak-light stress tolerance in cucumber seedlings. Seedlings grown in different ALA treatments $\left(0,10,20\right.$, or $30 \mathrm{mg}$ ALA $\cdot \mathrm{kg}^{-1}$ added to substrate) were exposed to low temperature $\left(16 / 8{ }^{\circ} \mathrm{C} \mathrm{light} / \mathrm{dark}\right)$ and weak light $\left(180 \mu \mathrm{mol} \cdot \mathrm{m}^{-2} \cdot \mathrm{s}^{-1}\right.$ photosynthetically active radiation) for two weeks. Treatment with ALA significantly alleviated the inhibition of plant growth, and enhanced leaf area, and fresh and dry weight of the seedlings under low-temperature and weak-light stress. Moreover, ALA increased chlorophyll (Chl) $a$, $\mathrm{Chl} b$, and $\mathrm{Chl} a+b$ contents. Net photosynthesis rate, stomatal conductance, transpiration rate, photochemical quenching, non-photochemical quenching, actual photochemical efficiency of photosystem II, and electron transport rate were significantly increased in ALA-treated seedlings. In addition, ALA increased root activity and antioxidant enzyme (superoxide dismutase, peroxidase, and catalase) activities, and reduced reactive oxygen species (hydrogen peroxide and superoxide radical) and malondialdehyde accumulation in the root and leaf of cucumber seedlings. These findings suggested that ALA incorporation in the substrate alleviated the adverse effects of low-temperature and weak-light stress, and improved Chl contents, photosynthetic capacity, and antioxidant enzyme activities, and thus enhanced cucumber seedling growth.
\end{abstract}

Keywords: ALA; abiotic stress; chlorophyll; photosynthesis; antioxidant enzyme

\section{Introduction}

Cucumber (Cucumis sativus L.), a member of the Cucurbitaceae family, is an important vegetable widely cultivated and consumed around the world [1]. Plants are challenged by numerous environmental stresses (e.g., high and low temperatures, salinity, light, drought, and heavy metal stress) that affect plant growth and productivity [2,3]. Low temperature and low-light stress are the most critical environmental factors that influence cucumber production in a solar greenhouse [2,4]. Plant exposed to low temperature and light stress exhibit a number of physiological and biochemical abnormalities, including reduction in chlorophyll biosynthesis, photosynthetic capacity, carbohydrate and nitrogen metabolism, nutrient uptake and accumulation, and overproduction of reactive oxygen species (ROS) [5]. Accumulation of ROS negatively affects enzyme activities, biosynthesis of carbohydrates, DNA, and proteins, and other biochemical activities, thus leading to oxidative stress [4,5]. In addition, ROS influence the expression of a number of genes involved in diverse processes such as growth, 
cell cycle, programmed cell death, abiotic stress responses, pathogen attack response, systemic signaling, and development [6]. The antioxidant defense system, which includes superoxide dismutase (SOD), peroxidase (POD), catalase (CAT), glutathione reductase (GR), and ascorbate peroxidase (APX), plays a crucial role in normalizing the production of ROS, thereby protecting plants from abiotic stresses $[6,7]$.

5-Aminolevulinic acid (ALA) is an essential biosynthetic precursor and is considered to be a plant growth regulator $[8,9]$. The compound is a key precursor in the biosynthesis of porphyrin compounds, such as chlorophyll, heme, and plant hormones [10]. In addition, ALA is involved in photosynthesis regulation under abiotic stress. Exogenous ALA application increases chlorophyll accumulation and chlorophyll fluorescence indices in lettuce and oilseed rape [11,12]. It has recently been reported that ALA regulates the expression level of fructose-1,6-bisphosphatase (FBP), triose-3-phosphate isomerase (TPI), and ribulose-1,5-bisphosphate carboxylase/oxygenase small subunit (RBCS), which activate the Calvin cycle of photosynthesis under drought stress [13]. In a previous study we observed that ALA regulates endogenous hormone and nutrient accumulation in cucumber to induce low-temperature stress tolerance [10]. It is also reported that ALA is involved in the chlorophyll biosynthesis pathway under salinity stress [14], and induces antioxidant enzyme activities and endogenous hormone accumulation under low-temperature stress in cucumber seedlings [10]. Previous studies demonstrated that foliar application of ALA may confer plant tolerance to diverse abiotic stresses, such as chilling, high temperature, salinity, drought, weak light, and heavy metals [14-16]. ALA influences a variety of physiological and biochemical activities of plants in response to abiotic stresses, including chlorophyll biosynthesis, nutrient uptake, and antioxidant enzyme activities $[14,16]$. Furthermore, ALA induces abiotic stress tolerance through activation of numerous types of transcription factors, signal transduction, and chlorophyll and carbohydrate biosynthesis [9]. These findings suggest that ALA can broadly reduce the detrimental effects of environmental influence.

During winter vegetable cultivation, plants are frequently exposed to low temperature and weak light intensity (predominantly clouds or fog), which can negatively influence production. Therefore, this study was designed to investigate the role of ALA in response to a combination (low temperature and weak light) of stresses on cucumber seedling growth, chlorophyll contents, photosynthetic capacity, antioxidant enzyme activity, and ROS accumulation. The information generated from this study will improve our understanding of responses to both stresses and will be useful for security of winter vegetable production.

\section{Materials and Methods}

\subsection{Plant Material and Experimental Setup}

Cucumber (Cucumis sativus 'Zhongnong 26') seeds were soaked in water at $55^{\circ} \mathrm{C}$ for $2-3 \mathrm{~h}$, and then germinated on moist gauze in the dark at $28^{\circ} \mathrm{C}$. The germinated seeds were transplanted into plug trays containing nursery substrate supplemented with ALA (Sigma, St Louis, MO, USA) and incubated at $28 / 18^{\circ} \mathrm{C}$ (light/dark) under $70 \%-75 \%$ humidity and $300-350 \mu \mathrm{mol} \cdot \mathrm{m}^{-2} \cdot \mathrm{s}^{-1}$ photosynthetically active radiation for $14 \mathrm{~h}$. The experiment consisted of four treatments based on different concentrations of ALA (applied as $\mathrm{kg}^{-1}$ substrate):

$\begin{array}{ll}\text { CK, } & \text { Control (no ALA) } \\ \text { T1, } & 10 \mathrm{mg} \text { ALA } \\ \text { T2, } & 20 \mathrm{mg} \text { ALA } \\ \text { T3, } & 30 \mathrm{mg} \mathrm{ALA}\end{array}$

The ALA concentrations were mixed with a constant weight of substrate $(\mathrm{kg})$. The substrates were used to fill a 32-cell seedling tray and a germinated seed was sown in each cell. At the first leaf (fully expanded) stage, the seedlings were transferred to a controlled artificial chamber under $16 / 8^{\circ} \mathrm{C}$ (day/night), photosynthetically active radiation of $180 \mu \mathrm{mol} \cdot \mathrm{m}^{-2} \cdot \mathrm{s}^{-1}$, and a photoperiod of $12 \mathrm{~h}$ for $21 \mathrm{~d}$ before sampling. The seedlings were irrigated at two-day intervals with Hoagland's solution to fulfil nutritional demand. Each treatment consisted of four replicates. 


\subsection{Measurement of Plant Growth Parameters}

Plant height, stem diameter, and fresh weight were measured with a ruler, vernier caliper, and electronic balance, respectively [10]. Fresh samples were placed in an oven at $105{ }^{\circ} \mathrm{C}$ for $30 \mathrm{~min}$, and then dried at $75^{\circ} \mathrm{C}$ [1]. Root vitality was determined using the triphenyl tetrazolium chloride method [2]. The seedling vigor index was calculated using the following formula [2].

$$
\text { Seedling Vigor Index }=\left(\frac{\text { Hypocotyl Diameter }}{\text { Plant Height }}+\frac{\text { Root Dry Weight }}{\text { Shoot Dry Weight }}\right) \times \text { Total Dry Weight }
$$

\subsubsection{Chlorophyll, Photosynthesis, and Chlorophyll Fluorescence Measurements}

Chlorophyll (Chl) contents were determined using an ethanol extraction method, as previously described [2]. Net photosynthetic rate $\left(P_{\mathrm{n}}\right)$, stomatal conductance $\left(G_{\mathrm{s}}\right)$, transpiration rate $\left(T_{\mathrm{r}}\right)$, and intercellular $\mathrm{CO}_{2}$ concentration $\left(C_{i}\right)$ on the fourth fully expanded leaf from the shoot tip were measured using a portable photosynthesis system (Li-6400XT, LI-COR, Inc., Lincoln, NE, USA).

The portable photosynthesis system was also used for measurement of chlorophyll fluorescence. The fourth fully expanded leaves from the shoot tip were adapted in the dark for 30 min prior to measurement. The maximum photochemical efficiency of photosystem II $\left(F_{\mathrm{v}} / F_{\mathrm{m}}\right)$, maximum antenna conversion efficiency $\left(F_{\mathrm{v}}{ }^{\prime} / F_{\mathrm{m}}{ }^{\prime}\right)$, photochemical quenching $(\mathrm{qP})$, nonphotochemical quenching (NPQ), the actual photochemical efficiency of photosystem II (ФPSII), and electron transport rate (ETR) were calculated [14].

\subsubsection{Determination of Root Activity}

The root activity was determined by TTC (Triphenyltetrazolium chloride) reduction method [2]. Briefly, $0.5 \mathrm{~g}$ fresh collected roots were cut into $2 \mathrm{~cm}$ length and put in $10 \mathrm{~mL} 0.5 \mathrm{mM}$ PBS buffer containing $0.4 \% \mathrm{TTC}(\mathrm{w} / \mathrm{v})$ and incubate for one hour at $37^{\circ} \mathrm{C}$. The reaction was stopped by using $2 \mathrm{~mL} \mathrm{H}_{2} \mathrm{SO}_{4}(1 \mathrm{~mol} / \mathrm{L})$ for $15 \mathrm{~min}$, and then remove all solutions, and then add $10 \mathrm{~mL} \mathrm{95 \%} \mathrm{ethanol} \mathrm{and}$ incubate for $24 \mathrm{~h}$ at room temperature (until root turn white). The absorbance was read at $485 \mathrm{~nm}$ using spectrophotometer.

Calculation formula:

Tetrazole reduction strength $(\mu \mathrm{g} / \mathrm{gFW} . \mathrm{h})=(\mathrm{OD}+0.0035) / 4^{*} \mathrm{~h}^{*} \mathrm{~W}^{*} 0.0022(\mathrm{~h}=4, \mathrm{~W}=0.4 \sim 0.5)$

\subsection{Measurement of $\mathrm{O}_{2}{ }^{--}, \mathrm{H}_{2} \mathrm{O}_{2}$, and Malondialdehyde Contents}

Superoxide radical $\left(\mathrm{O}_{2} \cdot{ }^{-}\right)$and hydrogen peroxide $\left(\mathrm{H}_{2} \mathrm{O}_{2}\right)$ contents were determined using assay kits (COMINBIO) with a UV-1800 spectrophotometer (Shimadzu, Kyoto, Japan) in accordance with the manufacturer's instructions. Malondialdehyde (MDA) content was measured using the thiobarbituric acid method [2].

\subsection{Activities of Antioxidant Enzymes}

Fresh leaves $(\sim 0.5 \mathrm{~g})$ were quickly ground with a pestle in an ice-cold mortar with $4 \mathrm{~mL}$ of

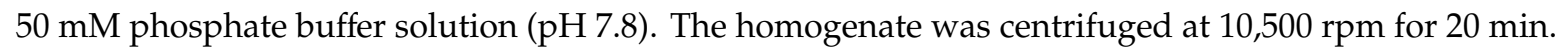
The supernatant was used to determine the activities of antioxidant enzymes. Superoxide dismutase (SOD) activity was measured, with some modifications, based on 50\% inhibition of the photochemical reduction of nitro blue tetrazolium at $560 \mathrm{~nm}$. Peroxidase (POD) activity was measured as the increase in absorbance at $470 \mathrm{~nm}$ using the method and catalase (CAT) activity was measured as the decline in absorbance at $240 \mathrm{~nm}$ [2]. 


\subsection{Statistical Analysis}

Each treatment consisted of four independent biological replicates and the entire experiment was repeated three times. The data were statistically analyzed using analysis of variance (ANOVA), and individual treatments were compared using the least significant difference test (LSD; $p=0.05)$ as implemented in Statistix 8.1 software.

\section{Results}

\subsection{Exogenous ALA Application Promoted Cucumber Seedlings Growth}

Application of ALA to the substrate significantly increased plant height, stem diameter, leaf area, fresh and dry weight, and seedling vigor index in cucumber seedlings, which were significantly reduced under low-temperature and weak-light stress (Figure 1). Compared with the control treatment (CK), the plant height, stem diameter, leaf area, fresh and dry weight, and seedling vigor index of cucumber seedlings increased by $14.4 \%, 13.4 \%, 63.1 \%, 54.3 \%, 54.5 \%$, and $53.8 \%$, respectively, in the T2 treatment. Growth parameters in the T1 and T3 treatments were not statistically different, but were significantly higher than those of the CK (Figure 1). The results suggested that ALA application alleviated the detrimental effects of the combined stress of low temperature and weak light, and thus enhanced cucumber seedling growth.
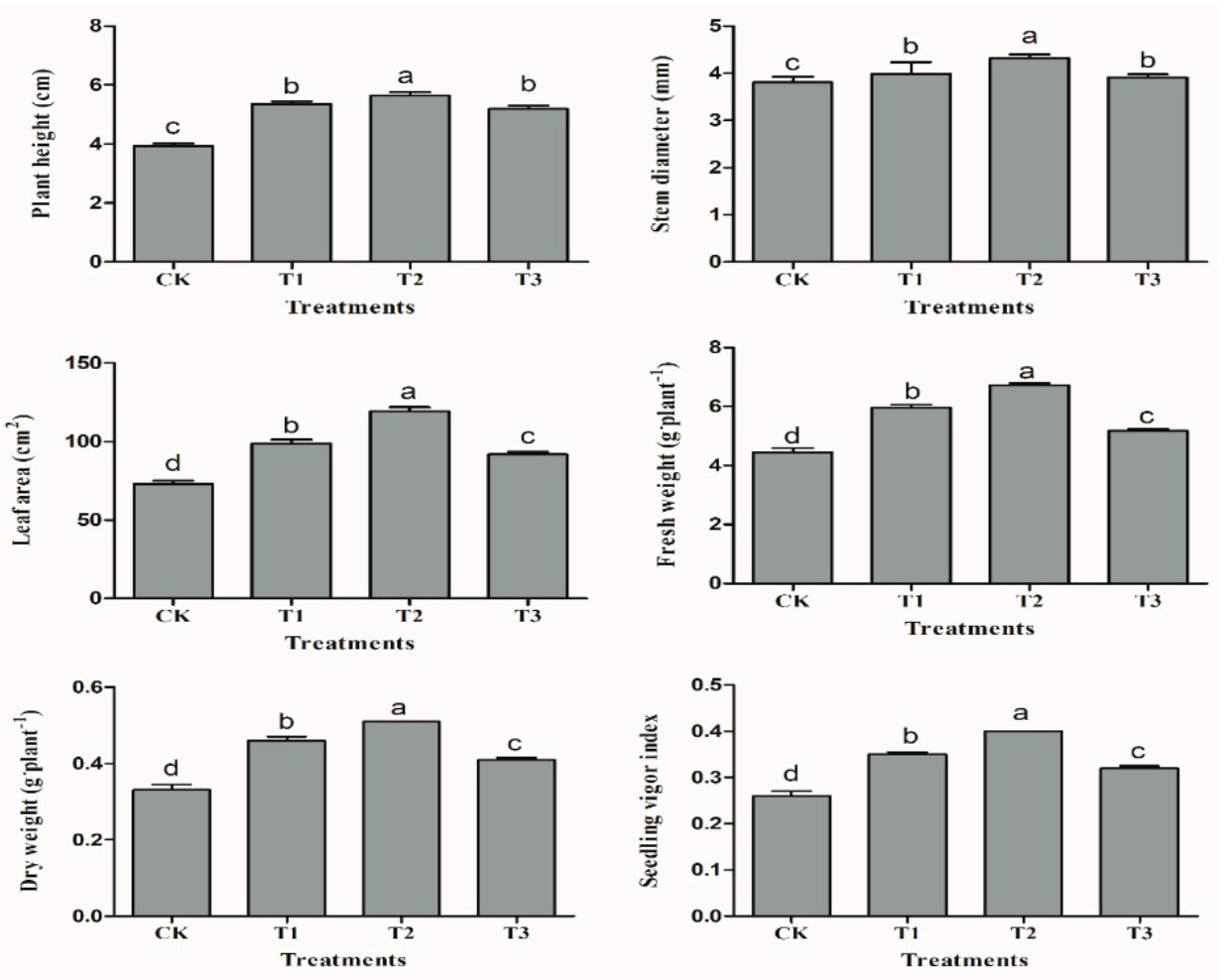

Figure 1. Effect of exogenous ALA application on growth of cucumber seedlings under low-temperature and weak-light stress. Data are the means of four replicates; error bars indicate the standard deviation. Treatments with the same lower-case letter are not significantly different (least significant difference test, $p=0.05)$. 


\subsection{Exogenous ALA Application Enhanced Root Activity of Cucumber Seedlings}

Root activity represents overall vigor, including root metabolic processes, enzyme activities, and water and nutrient absorption and uptake processes, thus it is considered to be an important index for plant response to environmental variables. The present results suggested that root vitality of cucumber seedlings was negatively affected by combined low-temperature and weak-light stress (Figure 2). The ALA-treated seedlings showed significantly enhanced tolerance to low-temperature and weak-light stress, and resulted in a significant increment in root vitality of the cucumber seedlings. Maximum root activity was observed in the T2 treatment and the lowest vitality was recorded in the CK.

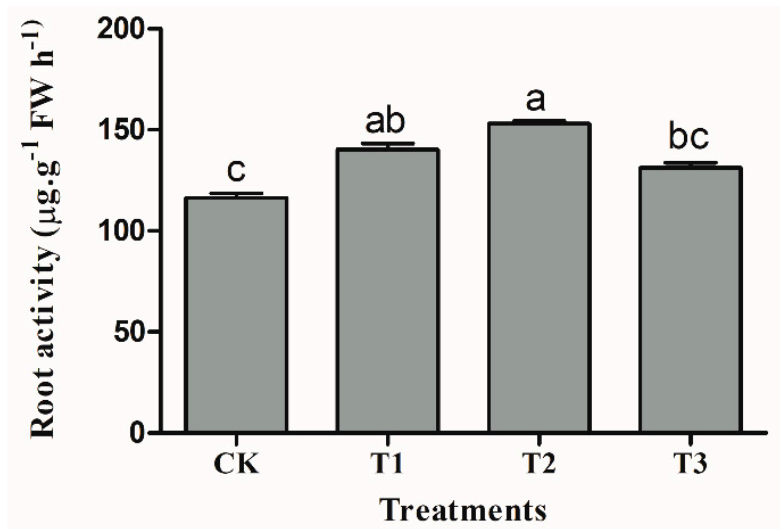

Figure 2. Effect of exogenous ALA application on root activity under low-temperature and weak-light stress. Data are the means of four replicates; error bars indicate the standard deviation. Treatments with the same lower-case letter are not significantly different (least significant difference test, $p=0.05$ ).

\subsection{Exogenous ALA Application Increased Chlorophyll Content of Cucumber Seedlings}

Chlorophylls (Chl) are extremely sensitive to abiotic stress and quickly degrade under an extreme stress intensity, which ultimately reduces photosynthetic capacity. The present results showed that low-temperature and weak-light stress induced a significant decrease in $\mathrm{Chl} a$, Chl b, and Chl $a+b$ contents, whereas the $\mathrm{Chl} a / b$ ratio was unchanged among the ALA treatments (Figure 3 ). Compared with the CK, the contents of $\mathrm{Chl} a, \mathrm{Chl} b$, and $\mathrm{Chl} a+b$ were increased by $22.14 \%, 28.26 \%$, and $23.59 \%$ respectively, in the T2 treatment, by $9.40 \%, 13.04 \%$, and $10.25 \%$ in the $\mathrm{T} 1$ and $6.04 \%, 8.70 \%$, and $6.70 \%$ in the T3 treatment (Figure 3). The differences in contents between the T1 and T2 treatments were non-significant, but were higher significantly than those of the CK and lower than those of the T2 treatment. The results showed that exogenous ALA increased Chl contents to reduce the harmful effect of low-temperature and weak-light stress.

The photosynthetic capacity was significantly enhanced by exogenous ALA application and low-temperature and weak-light stress. Significant increases in $P_{\mathrm{n}}, G_{\mathrm{s}}$, and $T_{\mathrm{r}}$ by $16.50 \%, 128.57 \%$, and $148.54 \%$, respectively, were observed compared with ALA-treated seedlings (T2; Figure 4). Similarly, the $\mathrm{T} 1$ and $\mathrm{T} 3$ treatments resulted in a significant increment in photosynthetic parameters compared with those of the CK. The $C_{\mathrm{i}}$ was slightly increased in ALA-treated seedlings, but the difference with the CK was non-significant. These findings indicated that ALA regulated chlorophyll contents and resulted in improved photosynthesis under combined low-temperature and weak-light stress. 

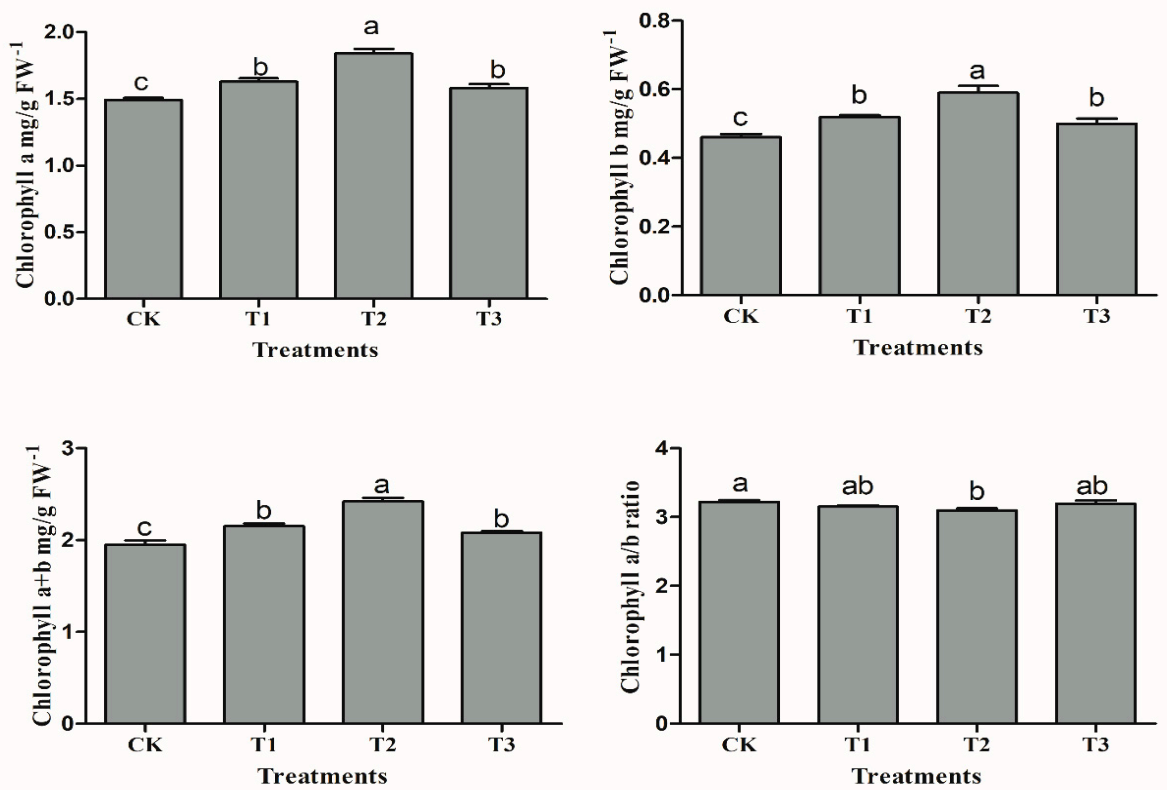

Figure 3. Effect of exogenous ALA application on chlorophyll contents of cucumber seedlings under low-temperature and weak-light stress. Data are the means of four replicates; error bars indicate the standard deviation. Treatments with the same lower-case letter are not significantly different (least significant difference test, $p=0.05$ ).
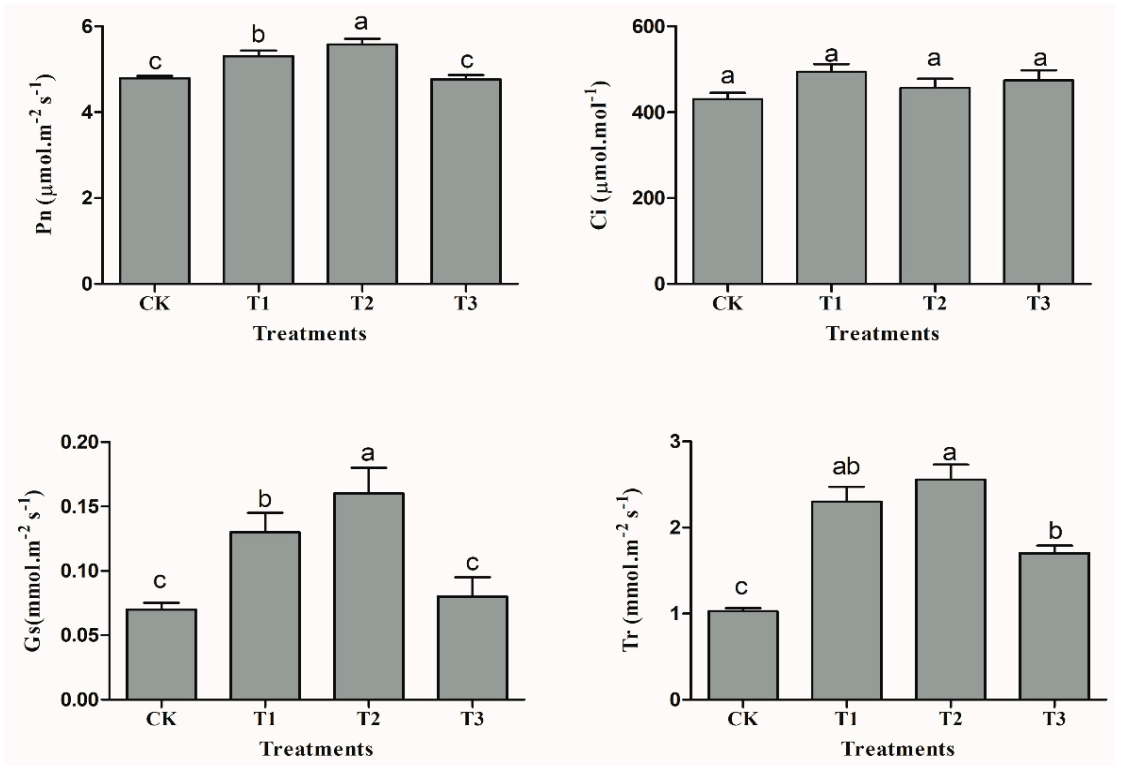

Figure 4. Effect of exogenous ALA on photosynthesis of cucumber seedlings under low-temperature and weak-light stress. Data are the means of four replicates; error bars indicate the standard deviation. Treatments with the same lower-case letter are not significantly different (least significant difference test, $p=0.05)$. $P_{\mathrm{n}}$, net photosynthetic rate; $G_{\mathrm{S}}$, stomatal conductance; $C_{\mathrm{i}}$, intercellular $\mathrm{CO}_{2}$ concentration; $T_{\mathrm{r}}$, transpiration rate.

\subsection{Effects of exogenous ALA Application on Chlorophyll Fluorescence}

Chlorophyll fluorescence analysis is an important and commonly used technique to investigate the plant photosynthetic capacity and response to stress. The present results indicated that $F_{\mathrm{v}} / F_{\mathrm{m}}$ and $F_{\mathrm{v}}{ }^{\prime} / F_{\mathrm{m}}{ }^{\prime}$ were non-significantly different among all treatments (Table 1). In general, ALA-treated seedlings showed a significant in $\mathrm{qP}$, ФPSII, and ETR compared with the CK. However, the opposite 
trend was observed for NPQ. These findings suggested that ALA played a significant role in abiotic stress tolerance and protected the photosynthetic machinery.

Table 1. Effects of exogenous ALA application in the substrate on chlorophyll fluorescence parameters of cucumber seedlings under low-temperature and weak-light stress.

\begin{tabular}{ccccccc}
\hline Treatment & $\mathbf{F}_{\mathbf{v}} / \mathbf{F}_{\mathbf{m}}$ & $\mathbf{F}_{\mathbf{v}}{ }^{\prime} / \mathbf{F}_{\mathbf{m}}{ }^{\prime}$ & $\mathbf{q P}$ & $\mathbf{N P Q}$ & $\mathbf{\Phi P S I I}$ & $\mathbf{E T R}$ \\
\hline CK & $0.60 \pm 0.02 \mathrm{a}$ & $0.48 \pm 0.09 \mathrm{a}$ & $0.28 \pm 0.07 \mathrm{~d}$ & $0.54 \pm 0.06 \mathrm{a}$ & $0.20 \pm 0.02 \mathrm{c}$ & $20.62 \pm 2.74 \mathrm{bc}$ \\
T1 & $0.61 \pm 0.03 \mathrm{a}$ & $0.46 \pm 0.04 \mathrm{a}$ & $0.55 \pm 0.08 \mathrm{~b}$ & $0.38 \pm 0.06 \mathrm{c}$ & $0.26 \pm 0.03 \mathrm{~b}$ & $21.73 \pm 2.76 \mathrm{ab}$ \\
T2 & $0.61 \pm 0.02 \mathrm{a}$ & $0.44 \pm 0.02 \mathrm{a}$ & $0.63 \pm 0.09 \mathrm{a}$ & $0.37 \pm .040 \mathrm{c}$ & $0.30 \pm 0.02 \mathrm{a}$ & $23.82 \pm 1.92 \mathrm{a}$ \\
T3 & $0.60 \pm 0.01 \mathrm{a}$ & $0.46 \pm 0.03 \mathrm{a}$ & $0.43 \pm 0.05 \mathrm{c}$ & $0.47 \pm 0.04 \mathrm{~b}$ & $0.21 \pm 0.02 \mathrm{c}$ & $19.22 \pm 1.48 \mathrm{c}$ \\
\hline
\end{tabular}

Data are the means of four replicates \pm standard deviation. Treatments with the same lower-case letter within a column are not significantly different (least significant difference test, $p=0.05$ ). $F_{\mathrm{v}} / F_{\mathrm{m}}$, maximum photochemical efficiency of photosystem II; $F_{\mathrm{v}}{ }^{\prime} / F_{\mathrm{m}}{ }^{\prime}$, maximum antenna conversion efficiency; qP, photochemical quenching; NPQ, non-photochemical quenching; $\Phi P S I I$, actual photochemical efficiency of photosystem II; ETR, electron transport rate.

\subsection{Exogenous ALA Application Promoted Antioxidant Enzyme Activities}

Overproduction of ROS and accumulation of MDA result in damage to chlorophylls, protein biosynthesis, and DNA, which ultimately results in oxidative stress. Plants have evolved a defense system (antioxidant enzymes), which control ROS overproduction under abiotic stress. In the present study, activities of antioxidant enzyme (SOD, POD, and CAT) were significantly increased in response to ALA treatment compared with those of the CK (Figure 5). The T2 exogenous ALA treatment significantly increased SOD, POD, and CAT activities by $83.91 \%, 20.27 \%$, and $27.96 \%$, in leaves and $74.58 \%, 63.97 \%$, and $56.53 \%$ in roots, respectively, compared with activities in the CK. The POD activity was significantly higher in T3 leaves and roots compared with those observed in the CK (Figure 5). These findings suggested that exogenous ALA may regulate the plant defense system to reduce the adverse effects of combined low-temperature and weak-light stress.
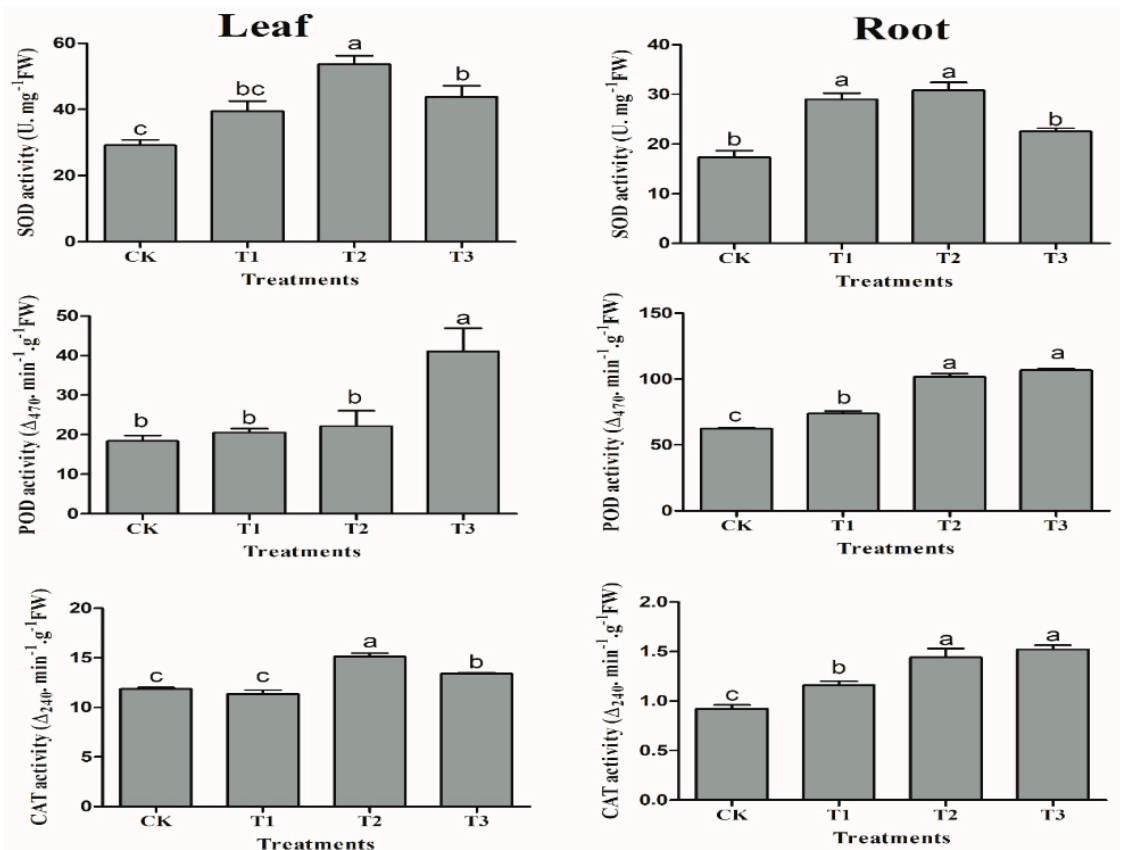

Figure 5. Effect of exogenous ALA application on antioxidant enzyme activities under low-temperature and weak-light stress in cucumber seedlings. Data are the means of four replicates; error bars indicate the standard deviation. Treatments with the same lower-case letter are not significantly different (least significant difference test, $p=0.05$ ). SOD, superoxide dismutase; POD, peroxidase; CAT, catalase. 


\subsection{Exogenous ALA Application Reduced $\mathrm{O}_{2}{ }^{--}, \mathrm{H}_{2} \mathrm{O}_{2}$, and $\mathrm{MDA}$ Accumulation}

Plant exposure to abiotic stress leads to overproduction of ROS and accumulation of MDA, which are highly reactive and toxic, and affect a variety of physiological and biochemical activities. The ROS and MDA contents were significantly higher in roots and leaves of the CK (Figure 6). The $\mathrm{O}_{2}{ }^{--}$content in the leaves and roots of CK seedlings was 1.27 and $2.39 \mu \mathrm{mol} \mathrm{g}^{-1} \mathrm{FW}$, respectively, and 0.41 and $1.24 \mu \mathrm{mol} \mathrm{g}^{-1} \mathrm{FW}$ in the $\mathrm{T} 2$ treatment. The $\mathrm{H}_{2} \mathrm{O}_{2}$ content in $\mathrm{CK}$ leaves and roots were 7.86 and $2.66 \mu \mathrm{mol} \mathrm{g}^{-1} \mathrm{FW}$, respectively, compared with 5.54 and $2.36 \mu \mathrm{mol} \mathrm{g}^{-1} \mathrm{FW}$, respectively, in the T2 treatment. The MDA content was significantly higher in the CK and decreased significantly in the T2 treatment (Figure 6). The ROS and MDA contents were significantly lower in the T1 and T2 treatments compared with those of the $\mathrm{CK}$, but the differences were non-significant for $\mathrm{T} 2$. These findings revealed that ALA application plays an important role in stabilizing ROS accumulation and biosynthesis under combined low-temperature and weak-light stress.
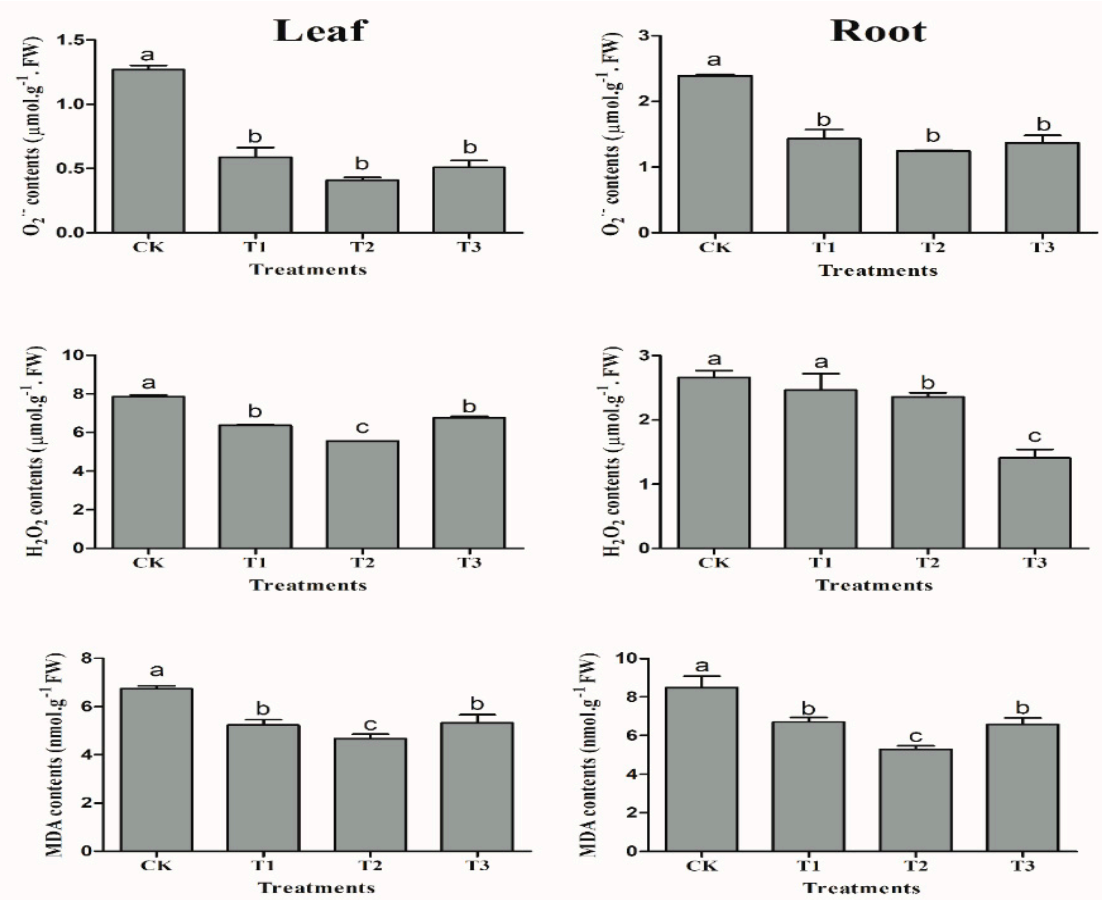

Figure 6. Effect of exogenous ALA application on reactive oxygen species and malondialdehyde contents under low-temperature and weak-light stress in cucumber seedlings. Data are the means of four replicates; error bars indicate the standard deviation. Treatments with the same lower-case letter are not significantly different (least significant difference test, $p=0.05$ ). $\mathrm{O}_{2}{ }^{-}$, superoxide radical; $\mathrm{H}_{2} \mathrm{O}_{2}$, hydrogen peroxide; MDA, malondialdehyde.

\section{Discussion}

Low-temperature and weak-light stress damage a variety of plant physiological and biochemical metabolic processes, and hence reduce yield [5]. ALA is a vital precursor of the tetrapyrrole biosynthesis pathway, and is considered to be a plant growth regulator and to regulate plant defense mechanisms to mitigate the harmful effects of abiotic stress $[9,10]$. As reported previously, low temperature has adverse impacts on cucumber seedlings, and results in a significant reduction in Chl accumulation and photosynthetic capacity [12,13]. Exogenous ALA application is involved in regulation of endogenous hormones, chlorophyll and nutrient accumulation, and the plant defense system, and significantly reduces the harmful effects of low temperature and improves cucumber seedling growth [10]. In the present study, the combined stress of low temperature and weak light imposed significant negative effects on cucumber seedling growth (Figure 1). These results were similar to those of previous studies, 
which reported that ALA stimulates the plant defense system to alleviate the harmful effects of salinity and low-temperature stress and promoted cucumber seedling growth [10,14].

Chlorophyll is highly sensitive to abiotic stress and is quickly degraded, and is also considered to be an indicator of chloroplast development and photosynthesis proficiency. Abiotic stresses increase degradation of Chl [1], which ultimately affects photosynthetic capacity [17-19]. Previous studies have reported that ALA improves $\mathrm{Chl}$ accumulation, photosynthetic capacity, and nutrient uptake to reduce the harmful impacts of salinity stress in Brassica napus L. [8,20]. In the present study Chl contents (Chl $a, \mathrm{Chl} b$, and $\mathrm{Chl} a+b$ ) were significantly increased in ALA-treated seedlings (Figure 3). These findings suggested that ALA increased Chl protection under combined low-temperature and weak-light stress. A recent study reported that exogenous ALA application regulates the ALA metabolic pathway and the transcript level of downstream genes (HEMA1, HEMH, CHLH, POR, and CAO), and ALA accumulation under salinity stress [14]. The activities of glutamyl-tRNA reductase and glutamate-1-semiadelhyde 2,1-aminomutase, which catalyze ALA biosynthesis [20,21], are improved in ALA-treated plants under abiotic stress [22-24]. Transcriptome analysis suggested that ALA regulates thousands of genes that are involved in Chl biosynthesis (ChlD, ChlH, and Chl1-1), photosynthesis, cell cycle, transaction factors, and defense-related genes $[11,25,26]$. The results are supported by previous findings that ALA activates chlorophyll biosynthesis and accumulation in bluegrass in response to osmotic stress [25]. These findings help to elucidate the specific role of ALA in the Chl biosynthesis pathway and stimulation of $\mathrm{Chl}$ biosynthesis-related gene expression and enzyme activities, thus enhancing $\mathrm{Chl}$ accumulation under low-temperature and weak-light stress.

In the present study, photosynthesis capacity and chlorophyll fluorescence are significantly affected by the combined stress of low temperature and weak light (Figures 3 and 4), and were enhanced significantly in ALA-treated seedlings. These findings indicate that ALA reduced the toxic effects of low-temperature and weak-light stress. ALA regulates photosynthesis-related parameters and transcript levels of RBCS, TPI, FBP, fructose-1,6-bisphosphate aldolase, and transketolase under drought stress in rapeseed plants [13]. In tomato plants, plasma membrane intrinsic proteins (PIPs) genes, such as PIP1 and PIP2, are regulated by exogenous ALA treatment. ALA not only enhances salinity stress tolerance, but also stimulates chlorophyll accumulation, chlorophyll fluorescence, and photosynthetic capacity [13]. In our previous study, we reported that exogenous ALA increases endogenous hormone accumulation, especially of 24-epibrassinolide, which regulates plant defense mechanisms, photosynthesis-related enzymes (such as Rubisco) and increasing the expression level of $r c a, r b c S$, and $r b c l$ involved in photosynthesis [27-29]. Transcriptome analysis suggested that photosystem II oxygen-evolving enhancer protein, photosystem I subunit, light-harvesting chlorophyll protein complex I and II, ferredoxin, $P_{\mathrm{n}}, T_{\mathrm{r}}, \Phi P S I I, E T R$, and $\mathrm{qP}$, are upregulated under ALA treatment [25]. ALA is a crucial precursor in the biosynthesis of all porphyrin compounds, such as chlorophyll, heme, and phytohormones $[8,12,13]$. These findings indicated that exogenous ALA application stimulated the biosynthesis pathway, that enhanced chlorophyll (Figure 3), photosynthetic capacity (Figure 4), and chlorophyll fluorescence (Table 1), and reduced the detrimental effects of low-temperature and weak-light stress.

Plants increase ROS and MDA accumulation under exposure to abiotic stress, which is highly toxic and causes damaging impacts on chlorophyll, lipid, protein, and carbohydrate biosynthesis [6]. To alleviate these harmful effects, plants have evolved a defense system to scavenge these toxic and reactive species through antioxidation of enzymatic and nonenzymatic systems, which leads to damage and may cause cell death $[6,30]$. In the present study, low temperature and weak light significantly reduced antioxidant enzyme activities and increased $\mathrm{O}_{2}{ }^{\bullet-}, \mathrm{H}_{2} \mathrm{O}_{2}$ and MDA accumulation, whereas the opposite trend was observed under ALA treatment (Figure 6). Root vitality is an indicator of the overall physiological and biochemical vigor of roots [2], which are extremely sensitive to abiotic stress. Root activity decreased rapidly, and ultimately affected water and nutrient uptake, thus causing negative effects on chlorophyll, photosynthesis, enzyme activities, and growth under abiotic stress [10]. In present study, ALA diminished the detrimental influence of low-temperature and weak-light stress 
and increase root activity (Figure 2). Previous studies have reported that ALA plays an important role in upregulation of plant defense mechanisms under abiotic stresses [10,14,25]. Antioxidant enzymes (SOD, POD, and CAT) are involved directly in scavenging $\mathrm{O}_{2}{ }^{\bullet-}$ and $\mathrm{H}_{2} \mathrm{O}_{2}$, and catalyzing their conversion to $\mathrm{H}_{2} \mathrm{O}$ and $\mathrm{O}_{2}$. The current results showed that exogenous ALA enhanced activities of the antioxidant enzymes SOD, POD, and CAT in leaves and roots of cucumber under low temperature and weak light (Figure 5). In cucumber seedlings, significantly enhanced activities of SOD, POD, CAT, APX (Ascorbate peroxidase), and GR (Glutathione reductase), and reduced ROS and MDA accumulation, are observed under ALA treatment combined with low-temperature stress [10]. Previous studies have reported that ALA activates the plant defense system and defense-related genes, such as genes encoding SOD, POD, CAT, and APX, in rice and strawberry under osmotic and photodynamic stresses and reduce overproduction of ROS and MDA [31-33]. ALA is a precursor of heme biosynthesis, and CAT, POD, and APX contain a heme prosthetic group [14], which might be the reason that antioxidant enzyme activities were stimulated in ALA-treated seedlings (Figure 5). A number of defense-related genes, such as those encoding ascorbate/glutathione, CAT, and POD, are upregulated in ALA-treated bluegrass seedlings under osmotic stress. These findings are in line with those of previous studies, in which exogenous ALA upregulated antioxidant enzyme activities and reduced ROS and MDA accumulation in cucumber seedlings under low-temperature stress $[8,10,12,33]$. Thus, it can be concluded that exogenous ALA application increased tolerance to low-temperature and weak-light stress, and stabilized ROS and MDA accumulation, thus enhancing cucumber seedling growth (Figure 1).

\section{Conclusions}

The present results have demonstrated that exogenous ALA application to cucumber alleviates growth inhibition by stimulating the plant defense system and stabilizing ROS accumulation, thus enhancing tolerance to low-temperature and weak-light stress. ALA is involved in chlorophyll biosynthesis and accumulation to enhance photosynthetic capacity, and may be involved in carbohydrate and amino acid biosynthesis, which contributes to improved plant growth under low-temperature and weak-light stress. This study provides novel evidence of the potent roles of ALA and provides insight into the ALA regulatory mechanism in conjunction with low-temperature and weak-light stress. ALA was applied through the substrate and induced a distinct response to combined low-temperature and weak-light stress. The results will be helpful for off-seasonal and protected vegetable production in a greenhouse.

Author Contributions: X.Y., A.A. and Y.L. conceived and designed the experiments. A.A. and J.W. performed the experiments. A.A. analyzed the data and wrote the manuscript. X.Y., C.H. and Y.L. contributed in reagents/materials/analysis tools. Y.L. and C.H. review the manuscript. All authors have read and agreed to the published version of the manuscript.

Funding: This work was supported by the National Key Research and Development Program of China (2016YFD0201006), Earmarked Fund for Modern Agro-industry Technology Research System (CARS-25-C-01), Science and Technology Innovation Program of the Chinese Academy of Agricultural Sciences (CAAS-ASTIP-IVFCAAS), and Key Laboratory of Horticultural Crop Biology and Germplasm Innovation, Ministry of Agriculture, China. The funders had no role in study design, data collection and analysis, decision to publish, or preparation of the manuscript.

Conflicts of Interest: The authors declare no conflict of interest.

\section{References}

1. Huang, S.; Li, R.; Zhang, Z.; Li, L.; Gu, X.; Fan, W.; Lucas, W.J; Wang, X.; Xie, B.; Ni, P.; et al. The genome of the cucumber, Cucumis sativus L. Nat. Genet. 2009, 41, 1275-1281. [CrossRef]

2. Anwar, A.; Bai, L.; Miao, L.; Liu, Y.; Li, S.; Yu, X.; Li, Y. 24-Epibrassinolide Ameliorates Endogenous Hormone Levels to Enhance Low-Temperature Stress Tolerance in Cucumber Seedlings. Int. Mol. Sci. 2018, 19, 2497. [CrossRef] [PubMed] 
3. Anwar, A.; Liu, Y.; Dong, R.; Bai, L.; Yu, X.; Li, Y. The physiological and molecular mechanism of brassinosteroid in response to stress: A review. Biol. Res. 2018, 51, 46. [CrossRef] [PubMed]

4. Xia, X.J.; Wang, Y.J.; Zhou, Y.H.; Tao, Y.; Mao, W.H.; Shi, K.; Asami, T.; Chen, Z.; Yu, J.Q. Reactive oxygen species are involved in brassinosteroid-induced stress tolerance in cucumber. Plant Physiol. 2009, 150, 801-814. [CrossRef] [PubMed]

5. Shu, S.; Tang, Y.; Yuan, Y.; Sun, J.; Zhong, M.; Guo, S. The role of 24-epibrassinolide in the regulation of photosynthetic characteristics and nitrogen metabolism of tomato seedlings under a combined low temperature and weak light stress. Plant Physiol. Bioch. 2016, 107, 344-353. [CrossRef] [PubMed]

6. Gill, S.S.; Tuteja, N. Reactive oxygen species and antioxidant machinery in abiotic stress tolerance in crop plants. Plant Physiol. Bioch. 2010, 48, 909-930. [CrossRef]

7. Xi, Z.; Wang, Z.; Fang, Y.; Hu, Z.; Hu, Y.; Deng, M.; Zhang, Z. Effects of 24-epibrassinolide on antioxidation defense and osmoregulation systems of young grapevines (V. vinifera L.) under chilling stress. Plant Growth Regul. 2013, 71, 57-65. [CrossRef]

8. Naeem, M.S.; Jin, Z.L.; Wan, G.L.; Liu, D.; Liu, H.B.; Yoneyama, K.; Zhou, W.J. 5-Aminolevulinic acid improves photosynthetic gas exchange capacity and ion uptake under salinity stress in oilseed rape (Brassica napus L.). Plant Soil 2010, 332, 405-415. [CrossRef]

9. Wu, Y.; Liao, W.; Dawuda, M.M.; Hu, L.; Yu, J. 5-Aminolevulinic acid (ALA) biosynthetic and metabolic pathways and its role in higher plants: a review. Plant Growth Regul. 2019, 87, 357-374. [CrossRef]

10. Anwar, A.; Yan, Y.; Liu, Y.; Li, Y.; Yu, X. 5-Aminolevulinic Acid Improves Nutrient Uptake and Endogenous Hormone Accumulation, Enhancing Low-Temperature Stress Tolerance in Cucumbers. Int. Mol. Sci. 2018, 19, 3379. [CrossRef]

11. Aksakal, O.; Algur, O.; Aksakal, F.; Aysin, F. Exogenous 5-aminolevulinic acid alleviates the detrimental effects of UV-B stress on lettuce (Lactuca sativa L) seedlings. Acta Physiol. Plant. 2017, 39. [CrossRef]

12. Liu, D.; Wu, L.; Naeem, M.S.; Liu, H.; Deng, X.; Xu, L.; Zhang, F.; Zhou, W. 5-Aminolevulinic acid enhances photosynthetic gas exchange, chlorophyll fluorescence and antioxidant system in oilseed rape under drought stress. Acta Physiol. Plant. 2013, 35, 2747-2759. [CrossRef]

13. Liu, D.; Hu, L.Y.; Ali, B.; Yang, A.G.; Wan, G.L.; Xu, L.; Zhou, W.J. Influence of 5-aminolevulinic acid on photosynthetically related parameters and gene expression in Brassica napus L. under drought stress. Soil Sci. Plant Nutr. 2016, 62, 254-262. [CrossRef]

14. Wu, Y.; Jin, X.; Liao, W.; Hu, L.; Dawuda, M.M.; Zhao, X.; Tang, Z.; Gong, T.; Yu, J. 5-Aminolevulinic Acid (ALA) Alleviated Salinity Stress in Cucumber Seedlings by Enhancing Chlorophyll Synthesis Pathway. Front. Plant Sci. 2018, 9, 635. [CrossRef] [PubMed]

15. Wang, L.J.; Jiang, W.B.; Huang, B.J. Promotion of 5-aminolevulinic acid on photosynthesis of melon (Cucumis melo) seedlings under low light and chilling stress conditions. Physiol. Plant. 2004, 121, 258-264. [CrossRef]

16. An, Y.; Feng, X.; Liu, L.; Xiong, L.; Wang, L. ALA-Induced Flavonols Accumulation in Guard Cells Is Involved in Scavenging $\mathrm{H}_{2} \mathrm{O}_{2}$ and Inhibiting Stomatal Closure in Arabidopsis Cotyledons. Front. Plant Sci. 2016, 7, 1713. [CrossRef]

17. Pandey, S.; Fartyal, D.; Agarwal, A.; Shukla, T.; James, D.; Kaul, T.; Negi, Y.K.; Arora, S.; Reddy, M.K. Abiotic Stress Tolerance in Plants: Myriad Roles of Ascorbate Peroxidase. Front. Plant Sci. 2017, 8, 581. [CrossRef]

18. Jin, S.H.; Li, X.Q.; Wang, G.G.; Zhu, X.T. Brassinosteroids alleviate high-temperature injury in Ficus concinna seedlings via maintaining higher antioxidant defence and glyoxalase systems. AoB PLANTS 2015, 7. [CrossRef]

19. Ogweno, J.O.; Song, X.S.; Shi, K.; Hu, W.H.; Mao, W.H.; Zhou, Y.H.; Yu, J.Q.; Nogués, S. Brassinosteroids Alleviate Heat-Induced Inhibition of Photosynthesis by Increasing Carboxylation Efficiency and Enhancing Antioxidant Systems in Lycopersicon esculentum. J. Plant Growth Regul. 2008, 27, 49-57. [CrossRef]

20. Tanaka, Y.; Tanaka, A.; Tsuji, H. Effects of 5-Aminolevulinic Acid on the Accumulation of Chlorophyll b and Apoproteins of the Light-Harvesting Chlorophyll a/b-Protein Complex of Photosystem II. Plant Cell Physiol. 1993, 34, 465-472.

21. Korkmaz, A.; Korkmaz, Y.; Demirkıran, A.R. Enhancing chilling stress tolerance of pepper seedlings by exogenous application of 5-aminolevulinic acid. Environ. Exp. Bot. 2010, 67, 495-501. [CrossRef]

22. Kwon, S.W.; Sohn, E.J.; Kim, D.W.; Jeong, H.J.; Kim, M.J.; Ahn, E.H.; Kim, Y.N.; Dutta, S.; Kim, D.-S.; Park, J. Anti-inflammatory effect of transduced PEP-1-heme oxygenase-1 in Raw 264.7 cells and a mouse edema model. Biochem. Bioph. Res. Co. 2011, 411, 354-359. [CrossRef] [PubMed] 
23. Nunkaew, T.; Kantachote, D.; Kanzaki, H.; Nitoda, T.; Ritchie, R. Effects of 5-aminolevulinic acid containing supernatants from selected Rhodopseudomonas palustris strains on rice growth under $\mathrm{NaCl}$ stress, with mediating effects on chlorophyll, photosynthetic electron transport and antioxidative enzymes. Electron. J. Biotechn. 2014, 17, 1. [CrossRef]

24. Tsuchiya, T.; Akimoto, S.; Mizoguchi, T.; Watabe, K.; Kindo, H.; Tomo, T.; Tamiaki, H.; Mimuro, M. Artificially produced [7-formyl]-chlorophyll $\mathrm{d}$ functions as an antenna pigment in the photosystem II isolated from the chlorophyllide a oxygenase-expressing Acaryochloris marina. BBA-Bioenergetics 2012, 1817, 1285-1291. [CrossRef]

25. Niu, K.; Ma, H. The positive effects of exogenous 5-aminolevulinic acid on the chlorophyll biosynthesis, photosystem and calvin cycle of Kentucky bluegrass seedlings in response to osmotic stress. Environ. Exp. Bot. 2018, 155, 260-271. [CrossRef]

26. Zhao, Y.Y.; Yan, F.; Hu, L.P.; Zhou, X.T.; Zou, Z.R.; Cui, L.R. Effects of exogenous 5-aminolevulinic acid on photosynthesis, stomatal conductance, transpiration rate, and PIP gene expression of tomato seedlings subject to salinity stress. Genet. Mol. Res. 2015, 14, 6401-6412. [CrossRef]

27. Wei, L.J.; Deng, X.G.; Zhu, T.; Zheng, T.; Li, P.X.; Wu, J.Q.; Zhang, D.W.; Lin, H.H. Ethylene is Involved in Brassinosteroids Induced Alternative Respiratory Pathway in Cucumber (Cucumis sativus L.) Seedlings Response to Abiotic Stress. Front. Plant Sci. 2015, 6, 982. [CrossRef]

28. Choudhary, S.P.; Yu, J.Q.; Yamaguchi-Shinozaki, K.; Shinozaki, K.; Tran, L.S. Benefits of brassinosteroid crosstalk. Trends Plant Sci. 2012, 17, 594. [CrossRef]

29. Xia, X.-J.; Huang, L.-F.; Zhou, Y.-H.; Mao, W.-H.; Shi, K.; Wu, J.-X.; Asami, T.; Chen, Z.; Yu, J.-Q. Brassinosteroids promote photosynthesis and growth by enhancing activation of Rubisco and expression of photosynthetic genes in Cucumis sativus. Planta 2009, 230, 1185. [CrossRef]

30. Zhu, T.; Deng, X.; Zhou, X.; Zhu, L.; Zou, L.; Li, P.; Zhang, D.; Lin, H. Ethylene and hydrogen peroxide are involved in brassinosteroid-induced salt tolerance in tomato. Sci. Rep. 2016, 6, 35392. [CrossRef]

31. Phung, T.H.; Jung, S. Differential antioxidant defense and detoxification mechanisms in photodynamically stressed rice plants treated with the deregulators of porphyrin biosynthesis, 5-aminolevulinic acid and oxyfluorfen. Biochem. Bioph. Res. Co. 2015, 459, 346-351. [CrossRef] [PubMed]

32. Cai, C.; He, S.; An, Y.; Wang, L. Exogenous 5-aminolevulinic acid improves strawberry tolerance to osmotic stress and its possible mechanisms. Physiol. Plantarum 2019. [CrossRef] [PubMed]

33. Anwar, A.; Li, Y.; He, C.; Yu, X. 24-Epibrassinolide promotes $\mathrm{NO}_{3}{ }^{-}$and $\mathrm{NH}_{4}{ }^{+}$ion flux rate and NRT1 gene expression in cucumber under suboptimal root zone temperature. BMC Plant Biol. 2019, 19, 225. 